\title{
Persistently higher serum SCD40L levels are associated with outcome in septic patients
}

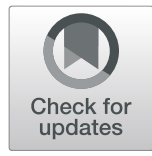

Yingjian Liang, Chengrui Zhu, Yini Sun, Zhiliang Li, Liang Wang, Yina Liu, Xin Li and Xiaochun Ma*

\begin{abstract}
Background: Soluble CD40 ligand (sCD40L) exhibits proinflammatory and procoagulant effects. Recent data indicated that SCD40L plays a significant role in septic patients. The aim of the present study was to determine sCD40L changes in surgical patients without sepsis (SWS) and surgical sepsis patients (SS) during the first 3 days after intensive care unit (ICU) admission and to observe the association between SCD40L and mortality.

Methods: Time changes in SCD40L levels were assessed for 3 days after ICU admission in 49 patients with SS and compared with those in 19 SWS patients. Serum SCD40L concentration was detected by ELISA. Survival at 28 days served as the endpoint.

Results: SS had significantly higher SCD40L levels than SWS and control patients. We observed an association between sCD40L levels $\geq 1028.75 \mathrm{pg} / \mathrm{mL}$ at day 2 and 28-day mortality (odds ratio $=7.888 ; 95 \%$ confidence interval $=1.758$ to $35.395 ; P=0.007$ ). We could not discover any significant differences in sex, presence of septic shock, site of infection, length of stay in the ICU, $\mathrm{PaO}_{2} / \mathrm{FiO}_{2}$ ratio, incidence of $\mathrm{AKI}, \mathrm{ARDS}$, or type of surgery between nonsurvivors and survivors.

Conclusions: Septic patients show persistently higher circulating SCD40L levels in the first 3 days after ICU admission, and serum sCD40L levels are associated with the mortality of patients with sepsis. Thus, serum SCD40L may be used as a reliable biomarker and therapeutic target in sepsis.
\end{abstract}

Keywords: Soluble CD40 ligand, Sepsis, Mortality

\section{Background}

Sepsis is the overwhelming inflammatory host response to the infectious agent causing the overexpression of inflammatory mediators [1]. Moreover, sepsis is also generally associated with coagulation abnormalities and presents as thromboembolic disease or clinically less apparent microvascular fibrin deposition [2]. In sepsis, inflammation and coagulation are cross-linked, and inflammation causes coagulation activation. In contrast, coagulation also affects the activation of inflammation, which promotes disease progression and leads to organ dysfunction [3].

\section{* Correspondence: cmu1hicu2002@sina.com}

Department of Critical Care Medicine, The First Hospital of China Medical University, North Nanjing Street 155, Shenyang 110001, Liaoning Province, China
CD40 ligand (CD40L) and the soluble form of CD40L $(\mathrm{sCD} 40 \mathrm{~L})$ are members of the tumor necrosis factor (TNF) family and are expressed in a variety of cell types, including B cells, epithelial cells, fibroblasts, endothelial cells (ECs), and platelets. CD40L and sCD40L exhibit proinflammatory and procoagulant effects $[4,5]$. Previous studies have found that serum CD40L levels are elevated in patients with sepsis and are associated with mortality in these patients [6-9].

In surgical patients, endothelial cell damage, inflammation, and coagulation changes occurred after surgery. Therefore, the purpose of this study was to determine sCD40L changes in surgical patients without sepsis (SWS) and in surgical sepsis patients (SS) during the first 3 days after ICU admission and to observe the relationship between sCD40L and mortality.

(c) The Author(s). 2021 Open Access This article is licensed under a Creative Commons Attribution 4.0 International License, which permits use, sharing, adaptation, distribution and reproduction in any medium or format, as long as you give appropriate credit to the original author(s) and the source, provide a link to the Creative Commons licence, and indicate if changes were made. The images or other third party material in this article are included in the article's Creative Commons licence, unless indicated otherwise in a credit line to the material. If material is not included in the article's Creative Commons licence and your intended use is not permitted by statutory regulation or exceeds the permitted use, you will need to obtain permission directly from the copyright holder. To view a copy of this licence, visit http://creativecommons.org/licenses/by/4.0/ The Creative Commons Public Domain Dedication waiver (http://creativecommons.org/publicdomain/zero/1.0/) applies to the data made available in this article, unless otherwise stated in a credit line to the data. 


\section{Methods}

\section{Design and subjects}

This was a prospective, observational study. Sixty-eight patients who underwent abdominal surgery were enrolled in the Intensive Care Unit of the First Affiliated Hospital, China Medical University from October 1, 2013 to February 28, 2014. These patients included 49 SS and 19 SWS. Six healthy controls were selected. The Ethical Committee of the First Affiliated Hospital of China Medical University approved this study. Because all the patients in our study were admitted to ICU with endotracheal intubation after general anesthesia, these patients were unconscious and unable to sign informed consent due to the influence of sedatives and analgesics. Thus, informed consent forms were signed by the patients' family members (No. 2015-113-2).

Forty-nine SS patients had abdominal infections or pulmonary infections in addition to other sites of infection. Sepsis and septic shock were diagnosed according to the Surviving Sepsis Campaign guidelines committee 2012 [10]. The exclusion criteria were age $<18$ years, pregnancy, lactation, human immunodeficiency virus (HIV) positive, hematological tumor, immunosuppressed, or undergoing steroid or radiation therapy.

\section{Variables recorded}

In all the patients, age, sex, Acute Physiology and Chronic Health Evaluation II (APACHE II) score, Sepsis-related Organ Failure Assessment (SOFA) score, sCD40L, International Society on Thrombosis and Haemostasis (ISTH) score, Japanese Association for Acute Medicine (JAAM) score, platelets, prothrombin time international normalized ratio (PT-INR), activated partial thromboplastin time (aPTT), fibrinogen, Ddimer, fibrinogen degradation product (FDP), leukocytes, lactate, site of infection, length of stay in the ICU, number of affected organs, acute kidney injury (AKI), acute respiratory distress syndrome (ARDS), pressure of arterial oxygen/fraction inspired oxygen $\left(\mathrm{PaO}_{2} / \mathrm{FiO}_{2}\right)$ ratio, sepsis-induced liver injury, invading organisms, and culprit organ with primary sepsis were recorded. Survival at 28 days was used as the study endpoint.

\section{Blood samples}

For patients, blood samples were drawn on days 1, 2 and 3 after ICU admission. For healthy controls, fasting blood samples were obtained at 8:00 am. Serum blood samples were centrifuged at $1500 \mathrm{~g}$ for $15 \mathrm{~min}$. The temperature was maintained at $4{ }^{\circ} \mathrm{C}$ in all steps after blood collection. Aliquots were stored at $-80^{\circ} \mathrm{C}$ for further analysis. Samples were thawed only once. Blood samples from each patient with SS were cultured and analyzed to identify the pathogenic bacteria.

\section{Soluble CD40L determination}

Serum sCD40L concentration was detected by enzymelinked immunosorbent assays (ELISA) from Life Science, Inc. (China). Each sample was measured in duplicate. The detection limit was $6.1 \mathrm{pg} / \mathrm{mL}$. The intratest variability among the duplicates of all samples was less than $10 \%$.

\section{Statistical analysis}

Continuous variables were analyzed as medians and interquartiles (IQ) 25 and 75\% (Q25-Q75), and categorical variables were analyzed as frequencies and percentages. Significant differences in continuous variables between groups were analyzed using the Mann-Whitney $\mathrm{U}$ test, and categorical variables were calculated using the chi-square test and Fisher's exact test, as appropriate. Receiver operating characteristic (ROC) curves were used to analyze serum sCD40L levels at days 1, 2 and 3 and establish cut off values. Survival analysis was performed with Kaplan-Meier method curves. Multiple logistic regression analysis was applied to predict 28-day mortality. To determine the association between $\mathrm{SCD} 40 \mathrm{~L}$ serum levels and other continuous variables at days 1, 2 and 3, Spearman's rank correlation coefficient was used. All $P$-values $<0.05$ were considered statistically significant. SPSS 20.0 (SPSS Inc., Chicago, IL, USA) was used for all statistical analyses.

\section{Results \\ Patient characteristics}

Baseline characteristics of 49 SS, 19 SWS and 6 age- and sex-matched healthy controls are shown in Table 1 . The levels of sCD40L in healthy controls were 469.50 (406.83-547.36) $\mathrm{pg} / \mathrm{mL}$, and the sCD40L levels in SWS and SS were significantly increased. The difference between the two groups was statistically significant (Table $1, P=0.000$ vs healthy controls). Compared with SWS, SS also exhibited increased APACHE-II $(P=$ $0.001)$, SOFA $(P<0.001)$, ISTH $(P<0.001)$, and JAAM $(P<0.001)$ scores; AKI $(P=0.000)$, ARDS $(P=0.000)$, PT-INR $(P=0.001)$, fibrinogen $(P=0.022)$, FDP $(P<$ $0.001)$, D-dimer $(P<0.001)$, and lactate $(P=0.006)$ levels; 28-day mortality $(P=0.001)$, longer length of stay in the ICU, and lower $\mathrm{PaO}_{2} / \mathrm{FiO}_{2}$ ratio (Table 1). However, type of surgery did not differ between the SS and SWS groups.

A total of 27 strains were isolated from the blood samples of 20 patients in the SS group, including seven strains with methicillin-resistant coagulase-negative Staphylococcus; five with Acinetobacter baumannii; five with non-Candida albicans; three with Enterococcus faecium, two each with methicillin-resistant Staphylococcus aureus, Pseudomonas aeruginosa, and Klebsiella pneumoniae; and one with Escherichia coli. More than two 
Table 1 Baseline demographic and clinical characteristics in the studied population group

\begin{tabular}{|c|c|c|c|c|}
\hline & $\begin{array}{l}\text { Healty control } \\
n=6\end{array}$ & $\begin{array}{l}\text { SS } \\
n=19\end{array}$ & $\begin{array}{l}\text { SWS } \\
n=49\end{array}$ & $P$ \\
\hline Sex (male/female) & $3 / 3$ & $12 / 7$ & $34 / 15$ & 0.586 \\
\hline Age (years)-median (p25-p75) & $53.00(42.25-62.00)$ & $76.00(71.00-81.00)$ & $61.00(45.00-73.00)$ & 0.005 \\
\hline sCD40L(pg/ml)-median (p25-p75) & $469.50(406.83-547.36)$ & $831.36(526.58-981.72)$ & $1022.68(554.85-2215.13)$ & 0.000 \\
\hline APACHE II score-median (p25-p75) & & $9.00(7.00-11.00)$ & $14.00(11.00-16.00)$ & 0.001 \\
\hline SOFA score-median (p25-p75) & & $1.00(0.00-2.00)$ & $8.00(6.00-10.00)$ & 0.000 \\
\hline ISTH score-median (p25-p75) & & $0.00(0.00-2.00)$ & $3.00(2.50-4.50)$ & 0.000 \\
\hline JAAM score-median (p25-p75) & & $1.00(0.00-2.00)$ & $4.00(3.00-5.00)$ & 0.000 \\
\hline PT-INR-median (p25-p75) & & $1.16(1.12-1.34)$ & $1.41(1.21-1.66)$ & 0.001 \\
\hline aPTT (seconds)-median (p25-p75) & & $41.10(36.10-81.40)$ & $49.40(41.55-60.85)$ & 0.080 \\
\hline Fibrinogen ( $g / L)$-median (p25-p75) & & $3.10(1.96-3.60)$ & $3.94(2.50-5.88)$ & 0.022 \\
\hline FDP (ug/dl)-median (p25-p75) & & $5.46(3.60-13.42)$ & $21.81(12.24-48.66)$ & 0.000 \\
\hline D-Dimer (ug/ml)-median (p25-p75) & & $1.71(0.80-3.58)$ & $4.81(3.24-10.11)$ & 0.000 \\
\hline Platelet-median*103/mm (p25-p75) & & $157.00(136.00-191.00)$ & $136.00(77.00-214.50)$ & 0.305 \\
\hline Leukocytes-median*103/mm (p25-p75) & & $7.87(5.28-11.90)$ & $10.62(7.50-15.44)$ & 0.030 \\
\hline Lactate (mmol/L)-median (p25-p75) & & $1.50(0.90-1.80)$ & $2.00(1.30-3.90)$ & 0.006 \\
\hline 28 days mortality (\%) & & 0/19 (0) & $20 / 49(40.82)$ & 0.000 \\
\hline Length of stay in the ICU (days)-median (p25-p75) & & $3.74(3-5)$ & $21.57(13-28)$ & 0.000 \\
\hline AKI-n (\%) & & $0 / 19(0)$ & $16 / 49(32.65)$ & 0.000 \\
\hline Sepsis-induced liver injury-n (\%) & & $0 / 19(0)$ & $3 / 49(6.12)$ & 0.277 \\
\hline ARDS-n (\%) & & 0/19 (0) & $21 / 49(42.86)$ & 0.000 \\
\hline $\mathrm{PaO}_{2} / \mathrm{FiO}_{2}$ ratio-median(p25-p75) & & $318.9(300-330)$ & $234.1(170-300)$ & 0.000 \\
\hline Subtotal gastrectomy-n(\%) & & 3/19 (15.79) & $10 / 49(20.41)$ & 0.549 \\
\hline Enteroanastomosis-n(\%) & & $8 / 19(42.11)$ & 19/49 (38.77) & 0.805 \\
\hline Cholecystectomy-n(\%) & & $3 / 19(15.79)$ & $8 / 49(16.33)$ & 0.958 \\
\hline Choledocholithotomy-n(\%) & & $5 / 19(26.31)$ & $12 / 49(24.49)$ & 0.878 \\
\hline
\end{tabular}

SWS Surgical patients without sepsis, SS Surgical sepsis patients, $p$ 25-75 Percentile 25th-75th, APACHE II Acute Physiology and Chronic Health Evaluation II, SOFA Sepsis-related Organ Failure Assessment, ISTH International Society on Thrombosis and Haemostasis, JAAM Japanese Association for Acute Medicine, PT-INR Prothrombin time international normalized ratio, aPTT Activated partial thromboplastin time, FDP Fibrinogen degradation product, AKI Acute kidney injury, ARDS Acute respiratory distress syndrome, $\mathrm{PaO}_{2} / \mathrm{FiO}_{2}$ Pressure of arterial oxygen/fraction inspired oxygen

strains were isolated from the blood samples of 8 patients.

\section{Demographic and clinical characteristics of nonsurvivors and survivors in surgical sepsis patients}

In total, 20 SS patients died, and 29 patients survived. The demographic and clinical features of these patients are shown in Table 2 and Supplemental Table 1. Nonsurviving patients had higher serum sCD40L $(P=0.009)$ and aPTT than surviving patients at day $2(P=0.020)$ and higher lactate at day $3(P=0.001)$. In addition, older age $(P=0.023)$ was observed in the group of nonsurviving patients compared with the group of surviving SS patients. No significant differences in sex, presence of septic shock, site of infection, length of stay in the ICU, $\mathrm{PaO}_{2} / \mathrm{FiO}_{2}$ ratio, incidence of AKI, ARDS, or type of surgery were noted between nonsurvivors and survivors. In addition, on days 1,2 , and 3 after ICU admission, no statistically significant differences in APACHE II score, SOFA score, ISTH score, JAAM score, PT-INR, fibrinogen, FDP, D-dimer, platelet and leukocytes were noted between the nonsurviving and surviving groups of SS.

\section{Predictive factors for 28-day mortality}

The area under the curve (AUC) for serum sCD40L levels at day $2(95 \%$ confidence interval $(\mathrm{CI})=0.570$ $0.871, P=0.009)$ could predict mortality at 28 days, and the sensitivity and specificity approached 60.0 and $79.3 \%$, respectively (Fig. 1). Kaplan-Meier survival analysis showed that patients with higher serum SCD40L levels at day $1(P=0.035)$, day $2(P=0.005)$, and day 3 $(P=0.003)$ had a higher risk of death at 28 days than patients with lower levels (Fig. 2). In addition, patient age $\geq$ 65 years (odds ratio $=7.929 ; 95 \% \mathrm{CI}=1.809$ to 34.750 ; $P=0.006)$ and serum sCD40L levels at day $2 \geq 1028.75$ $\mathrm{pg} / \mathrm{mL}$ (odds ratio $=7.888 ; 95 \% \mathrm{CI}=1.758$ to $35.395 ; P=$ 
Table 2 Biochemical characteristics of survivor and nonsurvivor surgical sepsis patients on day 2 of ICU admission

\begin{tabular}{|c|c|c|c|}
\hline & Survivor $(n=29)$ & Non-survivor $(n=20)$ & $P$ \\
\hline Gender (male/female) & $22 / 7$ & $12 / 8$ & 0.236 \\
\hline Age (years)-median(p25-p75) & $56.00(31.50-64.00)$ & $71.00(52.25-77.25)$ & 0.023 \\
\hline Septic shock- n (\%) & $17(58.6)$ & $10(50.0)$ & 0.551 \\
\hline Site of infection & & & 0.508 \\
\hline Respiratory - n (\%) & $5(17.2)$ & $5(25.0)$ & \\
\hline Abdominal - n (\%) & $24(82.8)$ & $15(75.0)$ & \\
\hline APACHE II score-median(p25-p75) & $12.00(8.00-16.50)$ & $14.00(11.25-17.00)$ & 0.156 \\
\hline SOFA score-median(p25-p75) & $6.00(5.00-10.00)$ & $8.50(6.00-10.00)$ & 0.216 \\
\hline ISTH score-median(p25-p75) & $4.00(2.00-5.00)$ & $3.00(3.00-4.75)$ & 0.901 \\
\hline JAAM score-median(p25-p75) & $4.00(2.50-5.00)$ & $4.00(2.50-4.75)$ & 0.835 \\
\hline PT-INR-median(p25-p75) & $1.36(1.25-1.72)$ & $138.5(128.25-170.75)$ & 0.760 \\
\hline aPTT (seconds)-median(p25-p75) & $51.00(43.60-66.95)$ & $68.65(53.20-113.95)$ & 0.020 \\
\hline Fibrinogen(g/L)-median(p25-p75) & $3.74(2.55-6.70)$ & $2.83(1.70-4.78)$ & 0.106 \\
\hline FDP (ug/dl)-median(p25-p75) & $16.96(10.43-33.01)$ & $20.40(7.37-32.33)$ & 0.823 \\
\hline D-Dimer (ug/ml)-median(p25-p75) & $3.96(2.95-7.61)$ & $3.86(2.19-7.86)$ & 0.502 \\
\hline Platelet- median*103/mm (p25-p75) & $109.00(47.00-191.00)$ & $124.50(65.25-174.25)$ & 0.903 \\
\hline Leukocytes-median*103/mm³ (p25-p75) & $13.71(6.83-17.93)$ & $13.91(9.06-19.22)$ & 0.376 \\
\hline Lactate (mmol/L)-median (p25-p75) & $2.10(1.30-3.15)$ & $2.75(1.65-5.60)$ & 0.203 \\
\hline sCD40L(pg/ml)-median (p25-p75) & $747.21(422.46-981.47)$ & $1214.72(696.28-2089.57)$ & 0.009 \\
\hline Length of stay in the ICU (days)-median (p25-p75) & $17.62(5-20)$ & $12.55(7-19)$ & 0.341 \\
\hline $\mathrm{AKI}-\mathrm{n}(\%)$ & $10 / 29(34.48)$ & $6 / 20(30.00)$ & 0.749 \\
\hline ARDS-n (\%) & $12 / 29(41.38)$ & $9 / 20(45.00)$ & 0.806 \\
\hline $\mathrm{PaO}_{2} / \mathrm{FiO}_{2}$ ratio-median $(\mathrm{p} 25-\mathrm{p} 75)$ & $232.9(170-300)$ & $236.0(170-310)$ & 0.900 \\
\hline Subtotal gastrectomy-n(\%) & $5 / 29(17.24)$ & $5 / 20(25.00)$ & 0.518 \\
\hline Enteroanastomosis-n(\%) & $11 / 29(37.93)$ & $8 / 20(40.00)$ & 0.889 \\
\hline Cholecystectomy-n(\%) & $5 / 29(17.24)$ & $3 / 20(15.00)$ & 0.839 \\
\hline Choledocholithotomy-n(\%) & $8 / 29(27.59)$ & $4 / 20(20.00)$ & 0.554 \\
\hline
\end{tabular}

p25-75 Percentile 25th-75th, APACHE II Acute Physiology and Chronic Health Evaluation II, SOFA Sepsis-related Organ Failure Assessment, ISTH Thrombosis and Haemostasis, JAAM Japanese Association for Acute Medicine, PT-INR Prothrombin time international normalized ratio, aPTT Activated partial thromboplastin time, FDP Fibrinogen degradation product, AKI Acute kidney injury, ARDS Acute respiratory distress syndrome, $\mathrm{PaO}_{2} / \mathrm{FiO}_{2}$ Pressure of arterial oxygen/fraction inspired oxygen

0.007) were significant predictive factors for 28-day mortality in multiple logistic regression analysis.

\section{Association between SCD40L levels and other clinical parameters in patients with surgical sepsis}

In addition, no relationship was observed between serum sCD40L levels and APACHE II, SOFA, ISTH, and JAAM score as well as PT-INR, fibrinogen, FDP, D-dimer, leukocyte, platelets and lactate levels in the SS group on days 1, 2, and 3 after ICU admission (Table 3).

\section{Discussion}

It can be concluded from this study that serum sCD40L levels in SS patients persistently increased significantly in the first 3 days after admission to the intensive care unit, and circulating sCD40L levels were increased on the second day of admission in the nonsurviving group compared with the surviving group. A novel finding of this study was that SWS patients also exhibited a slight increase in $\mathrm{SCD} 40 \mathrm{~L}$, but the level was not as great as that noted in SS patients.

Several studies have reported that sCD40L levels can predict the prognosis of patients with sepsis $[8,11]$. In our study, we found that serum sCD40L levels $\geq 1028.75$ $\mathrm{pg} / \mathrm{mL}$ at day 2 were associated with a higher death risk during the 28-day period in the multiple logistic regression analysis. Serum SCD40L levels could be used as a 28-day mortality biomarker. However, we did not find a relationship between sCD40L levels and sepsis severity criteria, such as APACHE II score and SOFA score. We only observed higher lactatemia in nonsurviving compared with surviving SS patients at day 3 after admission. 


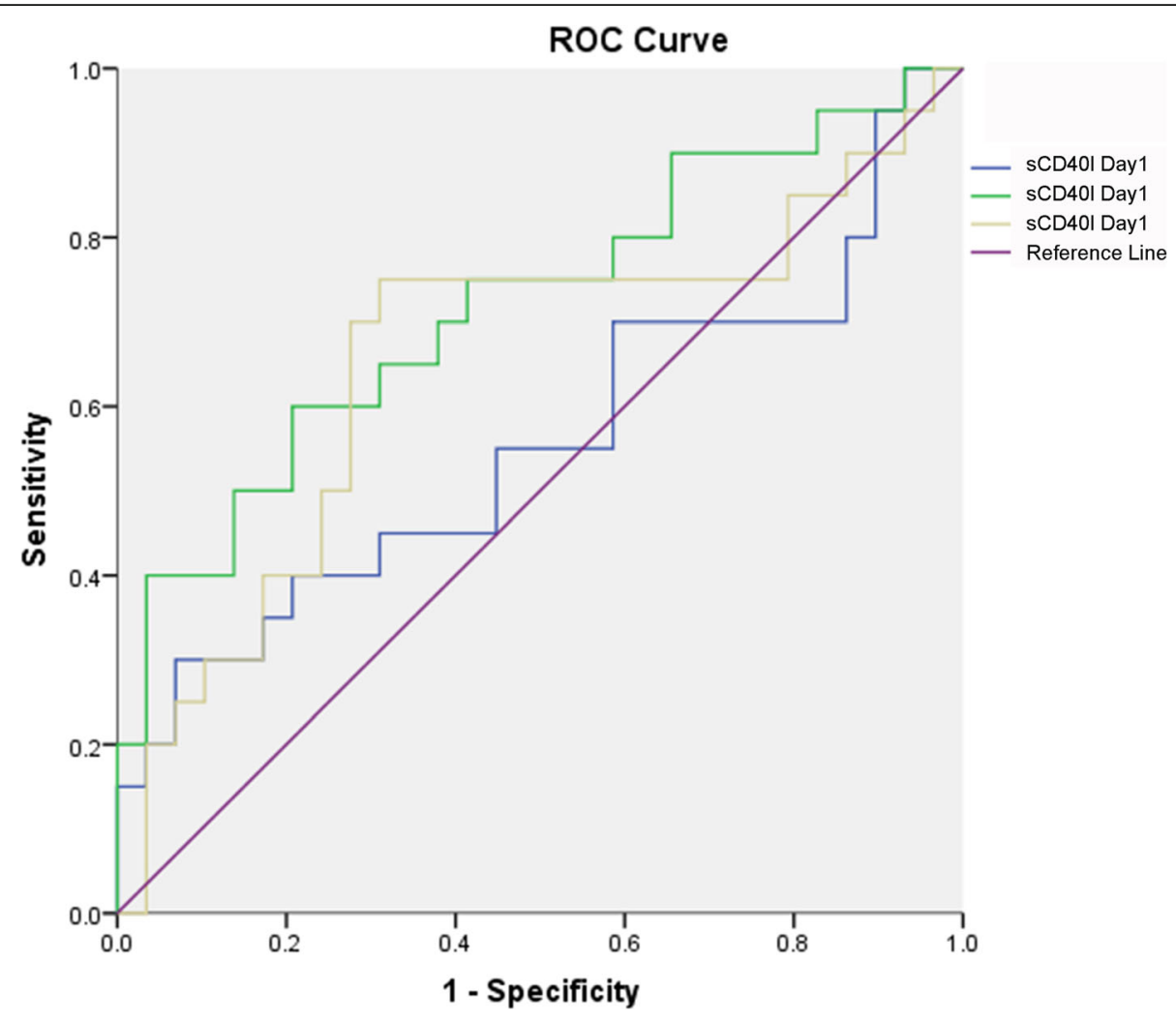

Fig. 1 Receiver operation characteristic analysis using sCD40L levels $\geq 1028.75 \mathrm{pg} / \mathrm{mL}$ at day 2 as a 28-day mortality predictor

Serum blood samples were obtained at ICU admission, but APACHE II or SOFA scores were calculated $24 \mathrm{~h}$ after admission to the ICU. We were not sure if this time gap affects the association between the two variables.

sCD40L has a dual prothrombotic and proinflammatory role. sCD40L connects to circulating monocytes through its receptor $\mathrm{CD} 40$, promoting their adhesion to the vascular endothelium. sCD40L also binds to CD40 on endothelial cell surfaces. Studies have shown that sCD40L stimulates its own expression by interacting with CD40 on the surface of these cells [12]. In sepsis, EC activation induced adhesion receptors and released inflammatory mediators, such as interleukin (IL)-1, IL-6 and tumor necrosis factor $[13,14]$. sCD40L also affects the neutrophil oxidative burst and neutrophil extracellular trap [5, 15]. Previous studies and our studies suggested that sCD40L exhibits no correlation with other coagulation factors except tissue factor (TF) [8]. The main reason was that activated ECs initiate the exogenous coagulation pathway by upregulating TF and downregulating the expression of thrombomodulin [16], favoring a local procoagulant status. In experimental models, sCD40L enhanced platelet activation and aggregation and induced thrombus formation [17]. All these effects contribute to the development of organ
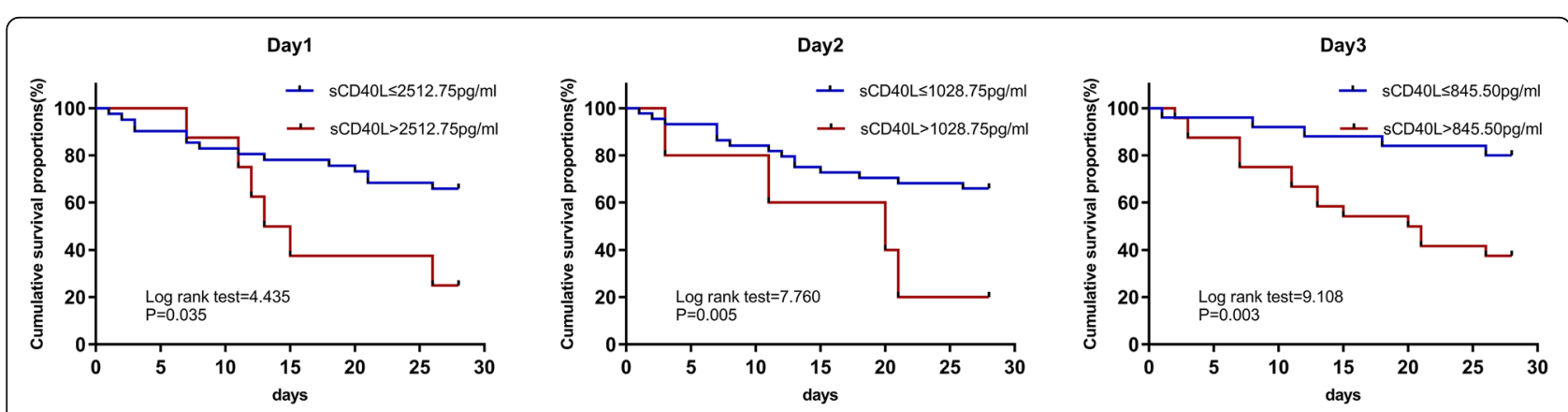

Fig. 2 Survival curves at 28 days according to serum SCD40L levels at days 1,2 and 3 in surgical sepsis patients admitted to the ICU 
Table 3 Association between sCD40L levels and other clinical parameters in patients with surgical sepsis

\begin{tabular}{|c|c|c|c|c|c|c|}
\hline & \multicolumn{2}{|c|}{ sCD40L day 1} & \multicolumn{2}{|c|}{ sCD40L day2 } & \multicolumn{2}{|c|}{ sCD40L day3 } \\
\hline & Rho & $\mathrm{P}$ & Rho & $\mathbf{P}$ & Rho & $P$ \\
\hline APACHE I| score & -0.215 & 0.138 & -0.045 & 0.761 & -0.208 & 0.151 \\
\hline SOFA score & -0.158 & 0.279 & -0.073 & 0.617 & 0.069 & 0.639 \\
\hline ISTH score & 0.016 & 0.914 & -0.051 & 0.726 & 0.098 & 0.501 \\
\hline JAAM score & -0.016 & 0.916 & 0.016 & 0.912 & 0.216 & 0.136 \\
\hline PT-INR & 0.146 & 0.318 & 0.166 & 0.255 & 0.055 & 0.708 \\
\hline $\mathrm{aPTT}$ & 0.132 & 0.367 & -0.027 & 0.851 & -0.043 & 0.769 \\
\hline Fibrinogen & -0.092 & 0.529 & -0.065 & 0.655 & -0.202 & 0.163 \\
\hline FDP & 0.131 & 0.370 & 0.137 & 0.347 & 0.085 & 0.562 \\
\hline D-Dimer & 0.171 & 0.240 & 0.077 & 0.600 & 0.069 & 0.636 \\
\hline Platelet & 0.046 & 0.752 & 0.122 & 0.405 & -0.003 & 0.983 \\
\hline Leukocytes & 0.223 & 0.124 & 0.158 & 0.277 & 0.061 & 0.679 \\
\hline Lactate & -0.050 & 0.733 & 0.194 & 0.181 & 0.111 & 0.447 \\
\hline
\end{tabular}

APACHE II Acute Physiology and Chronic Health Evaluation II, SOFA Sepsisrelated Organ Failure Assessment, ISTH Thrombosis and Haemostasis, JAAM Japanese Association for Acute Medicine, PT-INR Prothrombin time international normalized ratio, $a P T T$ Activated partial thromboplastin time, FDP Fibrinogen degradation product

dysfunction and death [18]. After intraoperative operation, ECs were damaged, and the body produced a stress response and inflammatory factors [19]. Therefore, the sCD40L level was also increased after surgery in non-sepsis patients. In sepsis patients, EC damage, intravascular microthrombus formation and production of inflammatory factors are more obvious, and sCD40L levels are much higher than those in patients who undergo simple surgery.

We did not find an association between serum sCD40L levels and platelet counts, although 95\% sCD40L was derived from platelets [20]. CD40L is stored in $\alpha$-granules in unstimulated platelets, undergoes conformational changes during platelet activation, migrates to the surface of platelets and is released into the blood [21]. Soluble CD40L enhances platelet activation, aggregation, and platelet-leukocyte conjugation. Therefore, SCD40L was implicated in platelet activation [12]. By interacting with ECs, activated platelets play a key role in inflammatory and procoagulant responses to a pathogen [22].

There were some limitations in our study. First, the sample size was relatively small. Second, the subjects were obtained from a single center. Third, we only determined sCD40L levels for 3 days after ICU admission but did not observe it for a week or longer; thus, we were unable to better conclude the time course of serum sCD40L levels in sepsis patients. Finally, an association between sCD40L levels and the activation function of platelets has been reported; we did not examine markers of platelet activation to analyze the relationship with sCD40L levels.

\section{Conclusions}

Septic patients show persistently higher circulating sCD40L levels in the first 3 days after ICU admission, and serum sCD40L levels are associated with the mortality of patients with sepsis. Thus, serum sCD40L levels may be used as a reliable biomarker and therapeutic target in sepsis.

\section{Supplementary Information}

The online version contains supplementary material available at https://doi. org/10.1186/s12871-021-01241-9.

Additional file 1: Supplemental Table 1. Biochemical characteristics of survivor and nonsurvivor surgical sepsis patients on days 1 and 3 after ICU admission.

\section{Abbreviations}

CD40L: CD40 ligand; sCD40L: Soluble CD40 ligand; TNF: Tumor necrosis factor; ECs: Endothelial cells; SWS: Surgical patients without sepsis;

SS: Surgical sepsis patients; APACHE II: Acute physiology and chronic health evaluation II; SOFA: Sepsis-related organ failure assessment;

ISTH: International society on thrombosis and haemostasis; JAAM: Japanese association for acute medicine; PT-INR: Prothrombin time international normalized ratio; aPTT: Activated partial thromboplastin time;

FDP: Fibrinogen degradation product; AKI: Acute kidney injury; ARDS: Acute respiratory distress syndrome; $\mathrm{PaO}_{2} / \mathrm{FiO}_{2}$ : Pressure of arterial oxygen/fraction inspired oxygen

\section{Acknowledgements}

Not applicable.

\section{Authors' contributions}

$Y J L$ and XM participated in the conception of the idea, conduct of the study, and preparation of the manuscript. CZ, YS, ZL provided data collection and critical revision. $L W, Y N L, X L$ participated in data analysis and critical revision. All authors reviewed and approved the submitted form of this manuscript.

\section{Funding}

This research did not receive any specific grant from funding agencies in the public, commercial, or not-for-profit sectors.

\section{Availability of data and materials}

The datasets used and/or analysed during the current study are available from the corresponding author on reasonable request.

\section{Ethics approval and consent to participate}

The Ethical Committee of the First Affiliated Hospital of China Medical University approved this study and the informed consents were signed by patients' family members.

\section{Consent for publication}

Not applicable.

\section{Competing interests}

The authors declare that they have no competing interests.

Received: 30 June 2020 Accepted: 11 January 2021

Published online: 22 January 2021

\section{References}

1. Semeraro N, Ammollo CT, Semeraro F, Colucci M. Sepsis, thrombosis and organ dysfunction. Thromb Res. 2012;129(3):290-5. 
2. Semeraro N, Ammollo CT, Semeraro F, Colucci M. Sepsis-associated disseminated intravascular coagulation and thromboembolic disease. Mediterr J Hematol Infect Dis. 2010;2(3):e2010024.

3. Levi M, Schultz M, van der Poll T. Sepsis and thrombosis. Semin Thromb Hemost. 2013;39(5):559-66.

4. Prasad KS, Andre P, He M, Bao M, Manganello J, Phillips DR. Soluble CD40 ligand induces beta3 integrin tyrosine phosphorylation and triggers platelet activation by outside-in signaling. Proc Natl Acad Sci U S A. 2003;100(21): 12367-71.

5. Chakrabarti S, Varghese S, Vitseva O, Tanriverdi K, Freedman JE. CD40 ligand influences platelet release of reactive oxygen intermediates. Arterioscler Thromb Vasc Biol. 2005;25(11):2428-34.

6. Inwald DP, Faust SN, Lister P, Peters MJ, Levin M, Heyderman R, et al. Platelet and soluble CD40L in meningococcal sepsis. Intensive Care Med. 2006:32(9):1432-7.

7. Chew M, Rahman M, Ihrman L, Erson A, Zhang S, Thorlacius H. Soluble CD40L (CD154) is increased in patients with shock. Inflamm Res. 2010; 59(11):979-82

8. Lorente L, Martin MM, Varo N, Borreguero-Leon JM, Sole-Violan J, Blanquer $\mathrm{J}$, et al. Association between serum soluble CD40 ligand levels and mortality in patients with severe sepsis. Crit Care. 2011;15(2):R97.

9. Lorente L, Martin MM, Perez-Cejas A, Ferreres J, Sole-Violan J, Labarta L, et al. Non-survivor septic patients have persistently higher serum $s C D 40 \mathrm{~L}$ levels than survivors. J Crit Care. 2017:41:177-82

10. Dellinger RP, Levy MM, Rhodes A, Annane D, Gerlach H, Opal SM, et al. Surviving sepsis campaign: international guidelines for management of severe sepsis and septic shock: 2012. Crit Care Med. 2013;41(2):580-637.

11. Lorente LMM, Pérez-Cejas A, Ferreres J, Solé-Violán J, Labarta L, Díaz C, Jiménez A. Non-survivor septic patients have persistently higher serum sCD40L levels than survivors. J Crit Care. 2017:41:177-82.

12. Hassan GS, Merhi Y, Mourad W. CD40 ligand: a neo-inflammatory molecule in vascular diseases. Immunobiology. 2012;217(5):521-32.

13. Dinarello CA. Interleukin-1 in the pathogenesis and treatment of inflammatory diseases. Blood. 2011;117(14):3720-32.

14. Hotchkiss RS, Karl IE. The pathophysiology and treatment of sepsis. N Engl J Med. 2003;348(2):138-50.

15. Perazzio SF, Soeiro-Pereira PV, Dos Santos VC, de Brito MV, Salu B, Oliva MLV, et al. Soluble CD40L is associated with increased oxidative burst and neutrophil extracellular trap release in Behcet's disease. Arthritis Res Ther. 2017;19(1):235

16. Damas JK, Jensenius M, Ueland T, Otterdal K, Yndestad A, Froland SS, et al. Increased levels of soluble CD40L in African tick bite fever: possible involvement of TLRs in the pathogenic interaction between rickettsia africae, endothelial cells, and platelets. J Immunol. 2006;177(4):2699-706.

17. Yacoub D, Hachem A, Theoret JF, Gillis MA, Mourad W, Merhi Y. Enhanced levels of soluble CD40 ligand exacerbate platelet aggregation and thrombus formation through a CD40-dependent tumor necrosis factor receptor-associated factor-2/Rac1/p38 mitogen-activated protein kinase signaling pathway. Arterioscler Thromb Vasc Biol. 2010;30(12):2424-33.

18. Rahman M, Zhang S, Chew M, Ersson A, Jeppsson B, Thorlacius H. Plateletderived CD40L (CD154) mediates neutrophil upregulation of mac-1 and recruitment in septic lung injury. Ann Surg. 2009;250(5):783-90.

19. Tran KD, Alabi RO, Odell K, Dye PK, Downes K, Sales CS. Measuring endothelial cell loss on DMEK grafts after transplantation in human cadaveric whole eyes: description of the technique and pilot study. Cornea. 2018;37(8):1075-80.

20. Andre P, Nannizzi-Alaimo L, Prasad SK, Phillips DR. Platelet-derived CD40L: the switch-hitting player of cardiovascular disease. Circulation. 2002;106(8): 896-9.

21. Henn V, Steinbach S, Buchner K, Presek P, Kroczek RA. The inflammatory action of CD40 ligand (CD154) expressed on activated human platelets is temporally limited by coexpressed CD40. Blood. 2001;98(4):1047-54.

22. Akinosoglou K, Alexopoulos D. Use of antiplatelet agents in sepsis: a glimpse into the future. Thromb Res. 2014;133(2):131-8.

\section{Publisher's Note}

Springer Nature remains neutral with regard to jurisdictional claims in published maps and institutional affiliations.

\section{Ready to submit your research? Choose BMC and benefit from:}

- fast, convenient online submission

- thorough peer review by experienced researchers in your field

- rapid publication on acceptance

- support for research data, including large and complex data types

- gold Open Access which fosters wider collaboration and increased citations

- maximum visibility for your research: over $100 \mathrm{M}$ website views per year

At $\mathrm{BMC}$, research is always in progress.

Learn more biomedcentral.com/submissions 